\title{
Influence of Growth Conditions on Magnetite Nanoparticles Electro-Crystallized in the Presence of Organic Molecules
}

\author{
Saba Mosivand ${ }^{1,2, *}$, Lorena M. A. Monzon ${ }^{1}$, Iraj Kazeminezhad ${ }^{2}$ and J. Michael D. Coey ${ }^{1}$ \\ 1 Physics Department, Trinity College, Dublin 2, Ireland; E-Mails: aranzazl@tcd.ie (L.M.A.M.); \\ jcoey@tcd.ie (J.M.D.C.) \\ 2 Physics Department, Faculty of Science, Shahid Chamran University, Ahvaz 61357-43337, Iran; \\ E-Mail: I.Kazeminezhad@scu.ac.ir \\ * Author to whom correspondence should be addressed; E-Mail: mosivans@tcd.ie; \\ Tel.: +353-1-8962-171; Fax: +353-1-6711-759.
}

Received: 29 March 2013; in revised form: 4 May 2013 / Accepted: 9 May 2013 /

Published: 17 May 2013

\begin{abstract}
Magnetite nanoparticles were synthesized by electrocrystallization in the presence of thiourea or sodium butanoate as an organic stabilizer. The synthesis was performed in a thermostatic electrochemical cell containing two iron electrodes with an aqueous solution of sodium sulfate as electrolyte. The effects of organic concentration, applied potential and growth temperature on particle size, morphology, structure and magnetic properties were investigated. The magnetite nanoparticles were characterized by X-ray diffraction, electron microscopy, magnetometry and Mössbauer spectrometry. When the synthesis is performed in the presence of sodium butanoate at $60{ }^{\circ} \mathrm{C}$, a paramagnetic ferric salt is obtained as a second phase; it is possible to avoid formation of this phase, increase the specific magnetization and improve the structure of the oxide particles by tuning the growth conditions. Room-temperature magnetization values range from 45 to $90 \mathrm{Am}^{2} \mathrm{~kg}^{-1}$, depending on the particle size, type of surfactant and synthesis conditions. Mössbauer spectra, which were recorded at $290 \mathrm{~K}$ for all the samples, are typical of nonstoichiometric $\mathrm{Fe}_{3-\delta} \mathrm{O}_{4}$, with a small excess of $\mathrm{Fe}^{3+}, 0.05 \leq \delta \leq 0.15$.
\end{abstract}

Keywords: magnetite nanoparticles; thiourea; sodium butanoate; electro-crystallization; magnetization; magnetite stoichiometry 


\section{Introduction}

In the last decade, magnetic nanostructures have attracted great attention because of their special properties, which differ significantly from those of the bulk materials. It is well known that magnetic nanoparticles are suitable for many industrial, biological and medical applications in the fields of pharmaceutical and cosmetic products, polishing, coatings, catalysis and semiconductors [1,2]. Recently, they have found new applications in areas such as cell separation and detection [3], inmuno-recognition and detection [4], tissue engineering and regenerative medicine [5], imaging [6], and in biosensors $[7,8]$.

Iron oxide nanoparticles are particularly useful and are being successfully employed in ferrofluids [9], hyperthermia-based therapy, controlled drug delivery [10,11], magnetic resonance imaging [12], drug delivery [13], as well as removal of heavy metals from waste water [14,15]. The magnetic properties have been discussed in several recent reviews [1,2,16-19]. They depend on many factors, including the particle size and shape, chemical composition, the type and density of defects and the interactions of the particles with the their neighbors [17].

To date, a wide range of different methods have been used to synthesize magnetite nanoparticles, which includes thermal decomposition [20], co-precipitation [21,22], ball milling [23], and solvothermal synthesis [24]. Co-precipitation is one of the simplest and oldest techniques and also the most common production method. However, this method usually generates particles with a wide particle size distribution, and may require secondary size selection [25]. Another difficulty in synthesizing $\mathrm{Fe}_{3} \mathrm{O}_{4}$ nanoparticles by chemical co-precipitation is the strong tendency of the particles to oxidize to $\alpha \mathrm{Fe}_{2} \mathrm{O}_{3}$, thereby greatly reducing their magnetization. Hence, the reaction should be performed under an inert atmosphere.

Electro-crystallization (electro-oxidation) is a less conventional method for preparing iron oxide nanoparticles. In this method, by applying an appropriate potential difference between two iron plates in an aqueous electrolyte solution, iron at the anode is oxidized to $\mathrm{Fe}^{2+}$ and $\mathrm{Fe}^{3+}$ and water is reduced to hydrogen and hydroxyl anions at the cathode. The iron ions and $\mathrm{OH}^{-}$in the solution react to form a black magnetite precipitate.

Up to now, there have been only a few reports of electrochemical synthesis of magnetite nanoparticles [26-29]. The mean particle size and particle size distribution can be tuned by growth parameters such as applied potential and temperature. Stabilizer agents can be added to the solution to avoid agglomeration.

It is possible to control the mean particle size and size distribution by adjusting the growth temperature and applied potential, in the presence of tetramethylammonium chloride as a stabilizer agent $[26,27]$. We have also found that the structural properties of electro-oxidized $\mathrm{Fe}_{3} \mathrm{O}_{4}$ nanoparticles are affected by the stabilizer concentration [29], and that the specific magnetization $\left(\sigma_{\mathrm{s}}\right)$ of magnetite can be controlled by the capping agent [30]. A great advantage of this synthetic route is that an inert atmosphere is not necessary to avoid oxidation of the nanoparticles.

The present report on the synthesis of magnetite nanoparticles focuses on two different organic molecules: thiourea $(\mathrm{Tu})$ and sodium butanoate $(\mathrm{Bu})$. We systematically examine the effect of concentration of organic additives, magnitude of applied potential and bath temperature on the structural and magnetic properties of the magnetite. We also analyze the relationship between growth 
conditions, specific magnetization and particle size, which is largely dependent on the concentration of organic molecules.

\section{Results and Discussion}

\subsection{XRD Results}

A typical XRD pattern with Rietveld analysis of a magnetite nanoparticle sample is shown in Figure 1. Based on XRD results, all products synthesized by this technique have the cubic spinel structure with space group $\mathrm{Fd} \overline{3} \mathrm{~m}$. The lattice parameters were all in the range $0.8371-0.8403 \mathrm{~nm}$, which may be comparable with the reference value for stoichiometric magnetite of $0.8396 \mathrm{~nm}$.

Figure 1. The XRD pattern and the Rietveld profile refinement, using the Fullprof program for magnetite nanoparticles prepared at $60{ }^{\circ} \mathrm{C}$ with $0.04 \mathrm{M} \mathrm{Tu}$ concentration, applying 5 volts across the electrochemical cell.

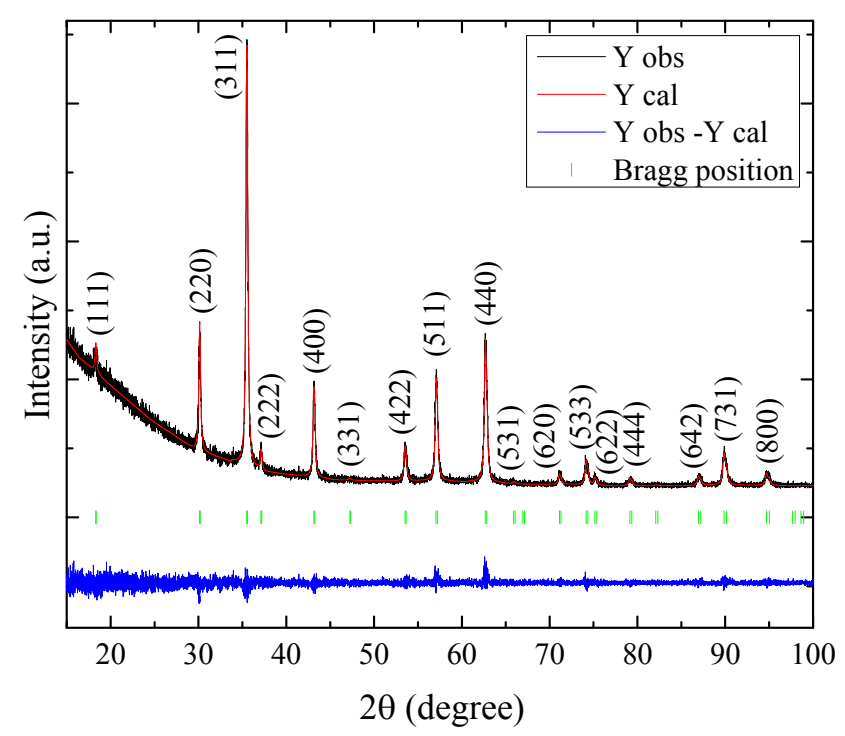

\subsection{Particle Size Distribution and Morphology}

The particle size was determined using Image-J like measurement software, for at least 100 particles of each sample, based on their electron microscope images. Then the mean particle size and size distribution histograms were obtained using SPSS statistical software. Figure 2 shows a sequence of typical SEM images of magnetite nanoparticles synthesized with $\mathrm{Tu}$ and $\mathrm{Bu}$, varying the concentration of organic agent, bath temperature and applied voltage. To the right, are shown the corresponding size distribution histograms. It can be seen that at high concentration of organics, and also at high voltage, a broad particle size distribution with some sheet-like structures mixed with agglomerated fine nanoparticles are observed. At lower growth temperature, smaller particles with a narrow size distribution were grown. Figure 3 shows TEM images of two typical samples prepared at the same experimental conditions $\left(5 \mathrm{~V} / 60{ }^{\circ} \mathrm{C} / 0.04 \mathrm{M}\right.$ concentration of $\mathrm{Bu}$ or $\mathrm{Tu}$ ) with different magnification. The crystalline magnetite nanoparticles are coated by a noncrystalline organic layer 2-3 nm thick. Figure 4 shows the mean particle size and standard deviation as a function of organic 
concentration, growth temperature and also applied potential for six groups of magnetite nanoparticles labeled by the concentration, temperature and voltage; for either $\mathrm{Tu}$ or $\mathrm{Bu}$; the concentration of organic is varied, keeping $V$ and $T$ at $5 \mathrm{~V}$ and $60{ }^{\circ} \mathrm{C}$, the temperature is varied keeping $V$ and $C$ at $5 \mathrm{~V}$ and $0.04 \mathrm{M}$, or the potential varied keeping $C$ and $T$ at $0.04 \mathrm{M}$ and $60^{\circ} \mathrm{C}$.

Figure 2. SEM images with size distribution histograms of magnetite nanoparticles prepared at different growth condition in the presence of $\mathrm{Bu}$ (left) and $\mathrm{Tu}$ (right).
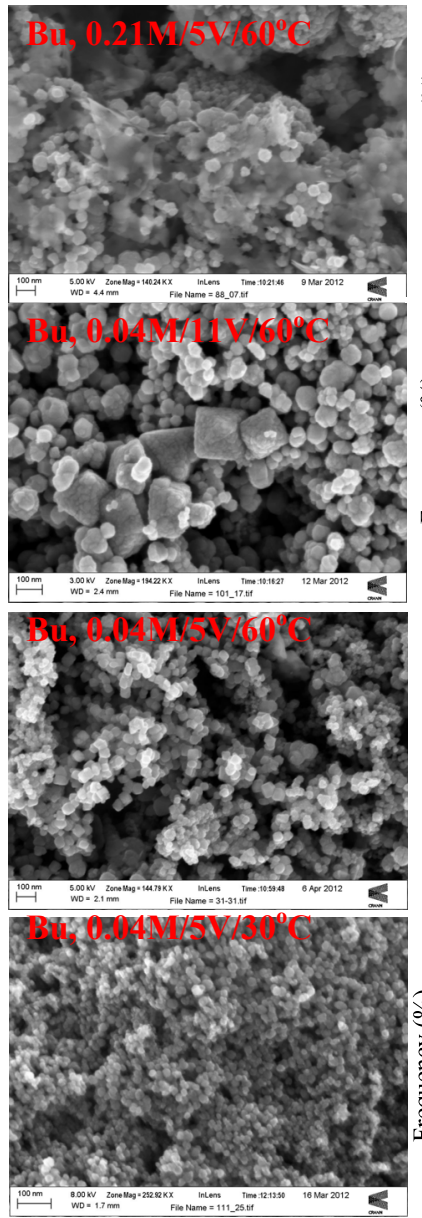
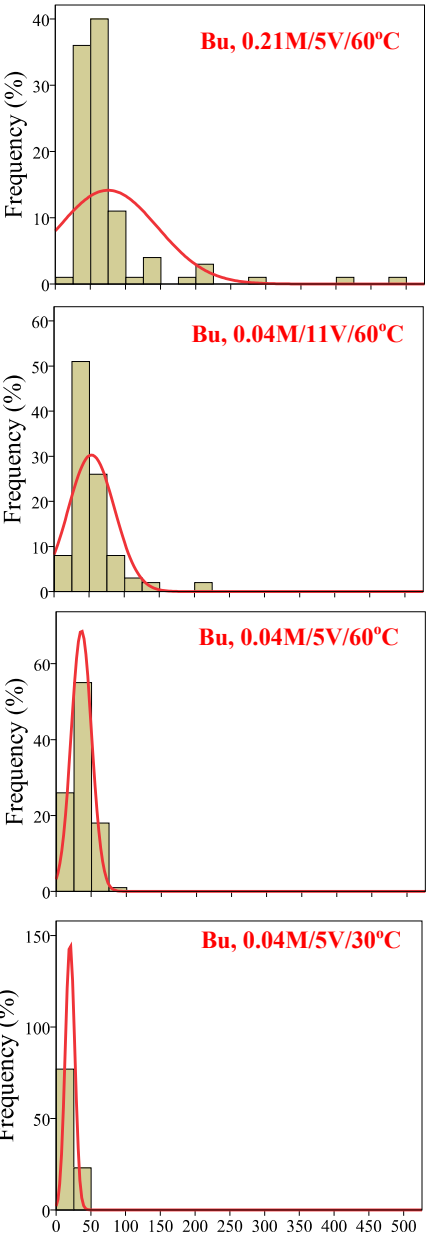

Particle size (nm)
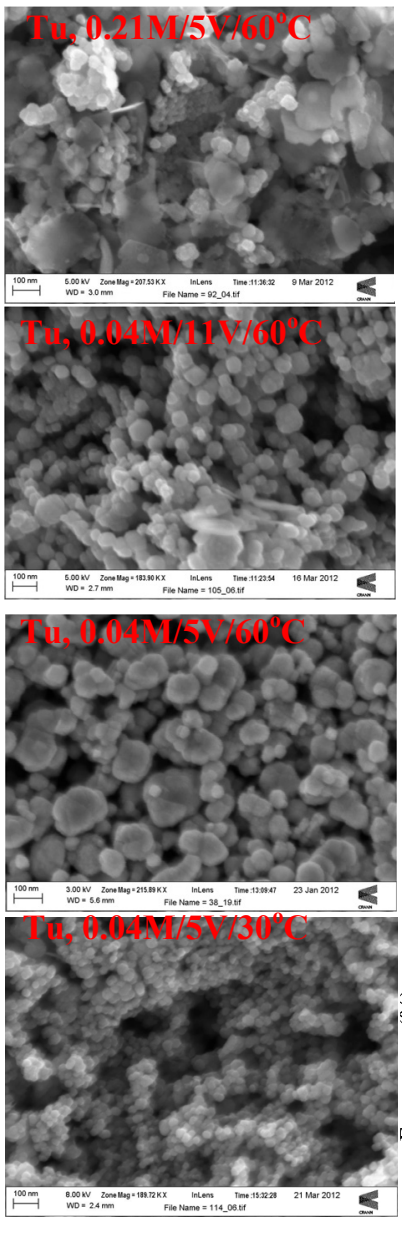
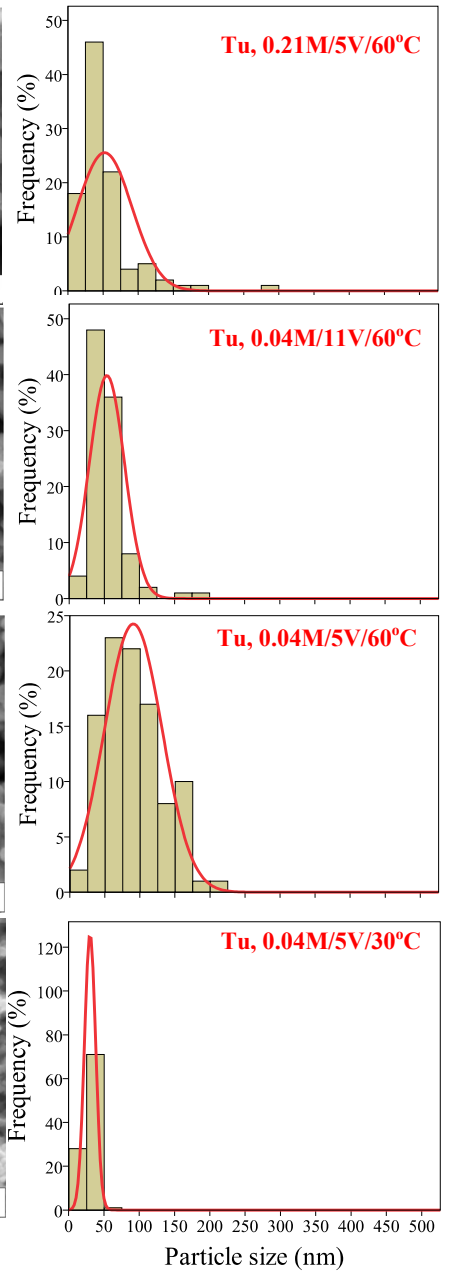

By comparing the mean particle size as a function of concentration in the case of $\mathrm{Tu}$, the particles synthesized at all $\mathrm{Tu}$ concentration are highly polydisperse. A way to reduce this polydispersity is to work at low temperature and carry out the synthesis at high overpotential. These results show that the size and morphology of electrosynthesized nanoparticles depend on the complex interplay of experimental conditions; the nature of the organic agent has a strong effect, but it is not readily predictable. The change in morphology and size with increasing additive concentration takes place because the flocculation effect of the organic influences the morphological evolution or the agglomeration of the nanoparticles. At $30^{\circ} \mathrm{C}$ this effect decreases and Bu molecules cover more fully the magnetite particles, preventing them from sticking to each other which leads to the formation of smaller particles. As can be seen, there is a direct relationship between temperature and mean particle size, and it is evident that the size distribution becomes broader as temperature increases. In addition, it 
can be seen that by applying high voltages, the particles synthesized with $\mathrm{Bu}$ are not uniform and a few typical octahedral magnetite crystals are seen in some of the SEM images. Furthermore, in this case, the particle size distribution becomes broader at high voltages. This could be related to increased chemical reactivity of the organic material.

Figure 3. HRTEM images of two typical samples prepared at $5 \mathrm{~V} / 60{ }^{\circ} \mathrm{C} / 0.04 \mathrm{M}$ concentration of $\mathrm{Bu}(\mathbf{t o p})$ and $\mathrm{Tu}$ (bottom), with different magnification.
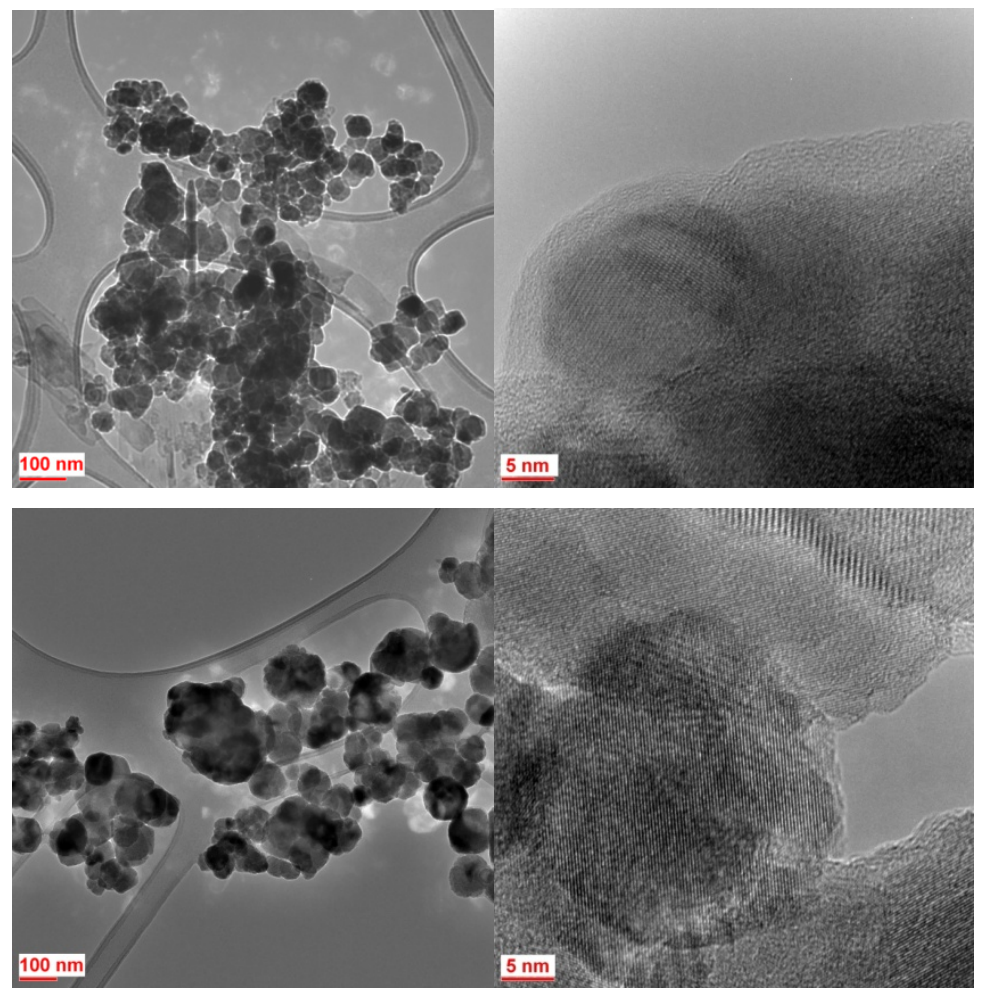

Figure 4. The dependence of mean particle size and $\sigma_{\mathrm{s}}$ versus organic concentration, applied potential and growth temperature of all magnetite nanoparticles. We vary $C_{\mathrm{Tu}}, \mathrm{Bu}$, with $V$ and $T$ at $5 \mathrm{~V}$ and $60{ }^{\circ} \mathrm{C}, V_{\mathrm{Tu}}$, Bu, with $C$ and $T$ at $0.04 \mathrm{M}$ and $60^{\circ} \mathrm{C}$, or $T_{\mathrm{Tu}}$, Bu, with $C$ and $V$ at $0.04 \mathrm{M}$ and $5 \mathrm{~V}$ (Trends are shown by the dashed lines).
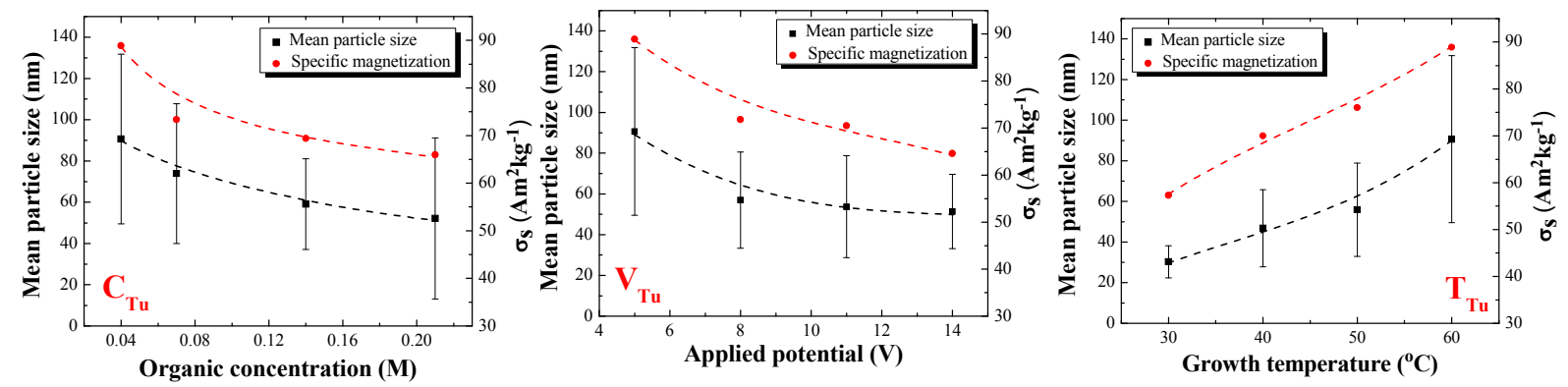
Figure 4. Cont.
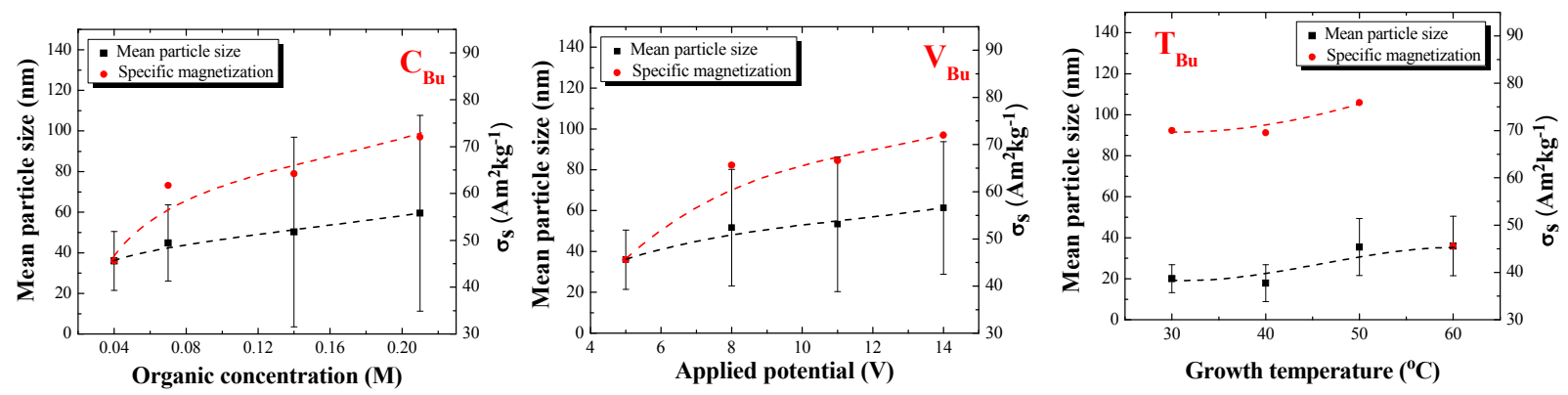

In general, concentration, voltage and temperature are all expected to drive the electrochemical reaction towards the formation of magnetite nanoparticles. At high concentration, applied voltage and temperature, the initial nuclei are more likely to cluster together, since they are all being formed at once. This leads to a smaller number of larger, more stable particles, as seen for $\mathrm{Bu}$ in Figure 4 . The behavior of $\mathrm{Tu}$ is different. Tu in water is protonated and therefore, positively charged, but this charge is not permanent. After applying a voltage to the electrochemical cell, these molecules migrate towards the cathode where $\mathrm{OH}^{-}$ions are being generated. The $\mathrm{OH}^{-}$ultimately deprotonates $\mathrm{Tu}$, which makes it less soluble. By increasing the concentration of $\mathrm{Tu}$, flocculation at the cathode is enhanced, causing formation of nanoparticles with different morphology.

\subsection{Magnetic Properties}

Figure 4 includes a plot of specific magnetization versus organic concentration, applied potential and growth temperature for all six groups of magnetite nanoparticles deduced from magnetization curves like those shown in Figure 5. There, data are presented for the $C_{\mathrm{Bu}}$ group. All samples are magnetically soft with only a little hysteresis, but the specific magnetization, $\sigma_{\mathrm{s}}$ is highly dependent on the nature of the organic molecules and growth conditions.

Figure 4 demonstrates that there is a direct correlation between mean particle size and specific magnetization. The smaller particles, which have a larger surface/volume ratio, have the lower magnetization. This might be due to more oxidation at the surface, but the Mössbauer spectra do not support this idea (Section 2.4). The reduction in magnetization could therefore be attributed to canted surface spins [31], or an increased nonmagnetic organic fraction in the samples. The larger particles exhibit a $\sigma_{\mathrm{s}}$ value close to that of bulk magnetite $\left(\sim 90 \mathrm{Am}^{2} \mathrm{~kg}^{-1}\right)$. The only exception is the sample synthesized with $0.04 \mathrm{M} \mathrm{Bu}$, applying $5 \mathrm{~V}$ at $60{ }^{\circ} \mathrm{C}$ where the lower $\sigma_{\mathrm{s}}$ value is due to the presence of a paramagnetic ferric salt formed between $\mathrm{Bu}$ and $\mathrm{Fe}^{3+}$, whose presence is evidenced by Mössbauer spectroscopy. $\mathrm{Bu}$ has a carboxylic group in its structure that chelates the $\mathrm{Fe}^{3+}$ in solution; therefore, a ferric salt is formed in the electrolyte formed at high temperature. We have observed this effect in a previous report, where we looked at 14 different agents at $60{ }^{\circ} \mathrm{C}$, but kept the concentration and voltage constant [30]. Although some magnetite samples have similar mean particle size, they may still exhibit different specific magnetization. This discussed further in Section 2.4. 
Figure 5. Room temperature magnetization curves of magnetite nanoparticles, belonging to the $C_{\mathrm{Bu}}$ group ( $V$ and $T$ at $5 \mathrm{~V}$ and $60^{\circ} \mathrm{C}$ ).

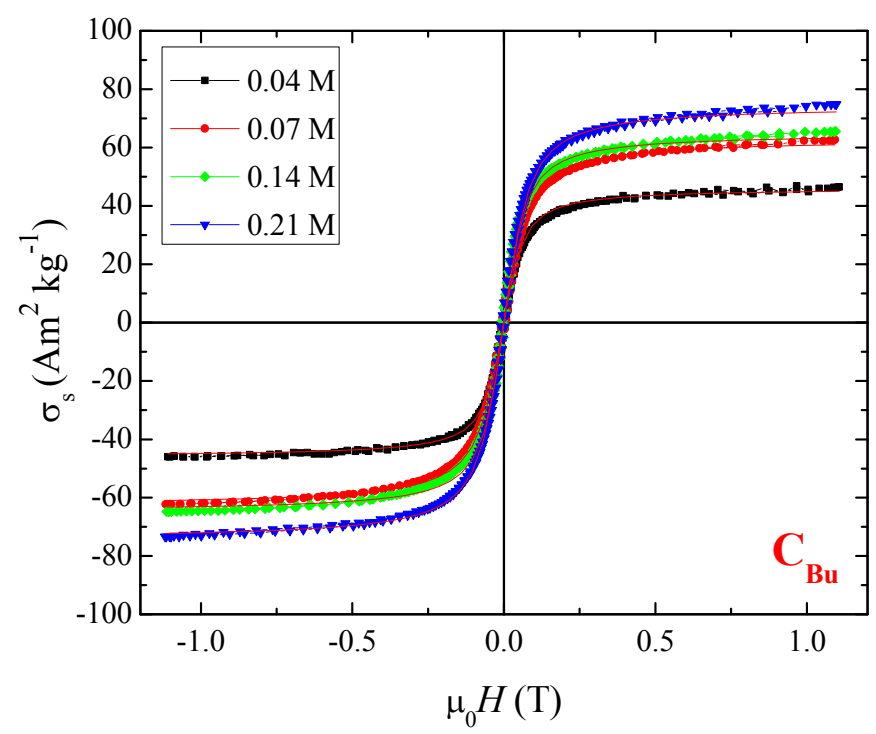

None of the magnetization curves exhibited any appreciable coercivity, and they were well fitted to the empirical expression

$$
M=M_{s} \tanh \left(H / H_{0}\right)
$$

where $M_{s}$ is the saturation magnetization, and $H_{0}$ is an effective field that governs the approach to saturation. It is readily estimated by extrapolating the slope at the origin, which reaches the saturation magnetization when $H=H_{0}$ [32]. Figure 6 shows a scatter plot of $M_{s}$ versus $H_{0}$ for all iron oxide samples discussed here, with the same units of $\mathrm{kA} \mathrm{m}^{-1}$ for both axes.

Figure 6. A scatter plot of $M_{s}$ versus $H_{0}$ for all the magnetite nanoparticles.

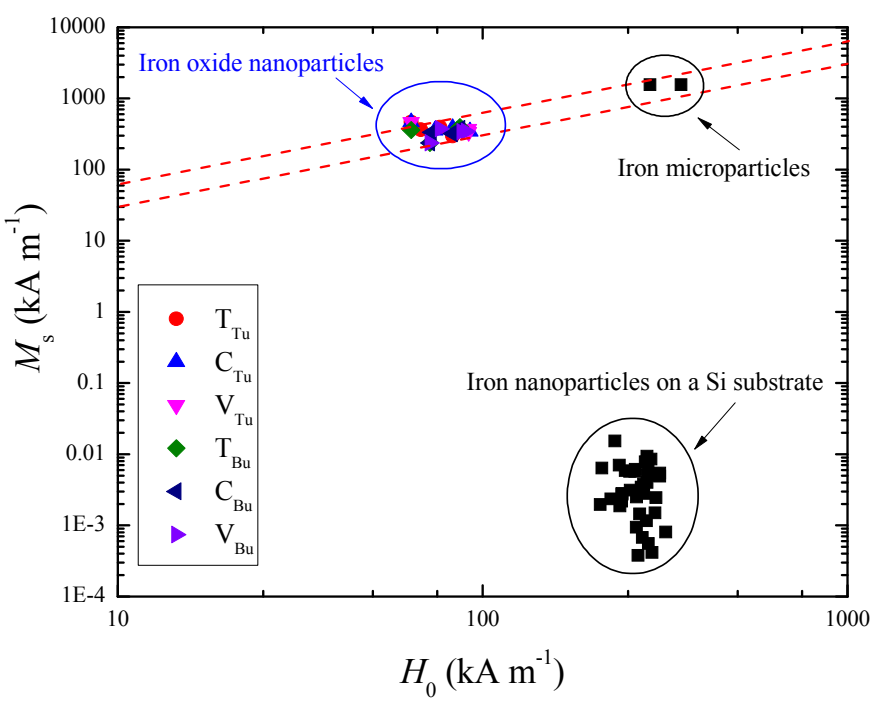

We include data on metallic iron microparticles and iron nanoparticles on an etched silicon substrate [33], which also exhibit characteristically anhysteretic magnetization curves with little temperature dependence below room temperature. These are the signs that the saturation of the magnetization is controlled by the magnetic dipolar field and not by magnetocrystalline anisotropy, 
which would normally give rise to temperature dependent coercivity at low temperature. If we assume a uniform demagnetizing field

$$
H_{\mathrm{d}}=-N M
$$

where $N$ is the demagnetizing factor, the two dashed lines in the Figure 5 show the expected trends for $N=1 / 3$ and $N=1 / 6$. The iron nanoparticles on silicon fall in a quite different area, because only a tiny fraction $\sim 10^{-5}$ of the sample volume is magnetic. It is likely that our magnetite particles have a vortex structure [34] for which $N_{\text {eff }} \approx 0.2$.

\subsection{Mössbauer Spectroscopy}

Figure 7 shows the experimental and fitted room-temperature Mössbauer spectra for magnetite nanoparticles prepared under different growth conditions, in the presence of $\mathrm{Tu}$ and $\mathrm{Bu}$. The spectra are well fitted by two magnetic sextets associated with magnetite, plus a central paramagnetic doublet, which accounts for the presence of a paramagnetic secondary phase associated with organometallic complexes containing $\mathrm{Fe}^{3+}$ and $\mathrm{Bu}$. It rapidly decreases in intensity by increasing the Bu concentration and applied voltage or decreasing the temperature. Another weak paramagnetic doublet with isomer shift $0.09 \mathrm{~mm} \mathrm{~s}^{-1}$ and quadrupole splitting $0.35 \mathrm{~mm} \mathrm{~s}^{-1}$ which is present in all the spectra is an artifact associated with iron in the beryllium window of the proportional counter; it corresponds to only about $3 \%$ of the total absorption (shown with a green dashed line in Figure 8). The dependence of the paramagnetic doublet contribution, the ratio of $\mathrm{Fe}^{2.5+}$ to $\mathrm{Fe}^{3+}$ and the nonstoichiometry parameter $\delta$ in the formula $\mathrm{Fe}_{3-\delta} \mathrm{O}_{4}$ as a function of growth parameters for all samples deduced from the intensity ratio of the two magnetite subspectra are presented in Figure 8.

Magnetite can exhibit a range of stoichiometry with a deficit of iron, and the extremes are $\delta=0$ (stoichiometric magnetite) and $\delta=0.67\left(\gamma-\mathrm{Fe}_{2} \mathrm{O}_{3}\right)$ in the formula $\mathrm{Fe}_{3-\delta} \mathrm{O}_{4}$. In stoichiometric magnetite, the iron in octahedral coordination (B-site) has an average electronic configuration of $\mathrm{Fe}^{2.5+}$, which arises from fast electron hopping among the iron on the octahedrally-coordinated sites. Hence, the ratio of the areas of the $\mathrm{Fe}^{3+}$ (A-site) to $\mathrm{Fe}^{2.5+}$ (B-site) spectra is expected to be 1:2. For non-stoichiometric magnetite, the vacancies are on B-sites, and the charge balance is preserved by a greater proportion of $\mathrm{Fe}^{3+}$ ions there. The two six-line subspectra are not attributed simply to A and B site iron, but to iron in an $\mathrm{Fe}^{3+}$ configuration (A-site and some B-site iron) and iron in an $\mathrm{Fe}^{2.5+}$ configuration involved in electron hopping (the remaining B-site iron) [30,35]. For $\mathrm{Fe}^{3+}$ and $\mathrm{Fe}^{2.5+}$, isomer shifts are $0.22 \pm 0.02$ and $0.45 \pm 0.05 \mathrm{~mm} / \mathrm{s}$, line width are $0.24 \pm 0.04$ and $0.45 \pm 0.11 \mathrm{~mm} / \mathrm{s}$, quadrupole shifts are $0.02 \pm 0.02$ and $0.25 \pm 0.25 \mathrm{~mm} / \mathrm{s}$, and hyperfine fields are $48.5 \pm 0.5$ and $44.4 \pm 0.9 \mathrm{~T}$, respectively. For all samples, the ratio of $\mathrm{Fe}^{2.5+}$ to $\mathrm{Fe}^{3+}$ is presented in Figure 8 together with the iron deficit $\delta$. For the sample produced in the presence of $0.04 \mathrm{M} \mathrm{Bu}$, applying $5 \mathrm{~V}$ at $60^{\circ} \mathrm{C}, \delta$ is 0.05 . It changes to 0.14 , 0.10 and 0.07 , by changing the $\mathrm{Bu}$ concentration, applied voltage or growth temperature to $0.21 \mathrm{M}$, $14 \mathrm{~V}$ and $30{ }^{\circ} \mathrm{C}$, respectively. Also in the case of $\mathrm{Tu}$, this parameter is 0.10 for the sample prepared with $0.04 \mathrm{M} \mathrm{Tu}$, applying $5 \mathrm{~V}$ at $60{ }^{\circ} \mathrm{C}$ and it changes to $0.08,0.08$ and 0.15 by changing the $\mathrm{Tu}$ concentration, applied voltage or growth temperature to $0.21 \mathrm{M}, 14 \mathrm{~V}$ and $30{ }^{\circ} \mathrm{C}$, respectively. Based on these results, the sample prepared in the presence of $\mathrm{Bu}$, with chemical formula $\mathrm{Fe}_{2.95} \mathrm{O}_{4}$ is closer to stoichiometric magnetite than any of the others. 
Figure 7. Experimental and fitted room-temperature Mössbauer spectra for magnetite nanoparticles prepared at different growth condition.
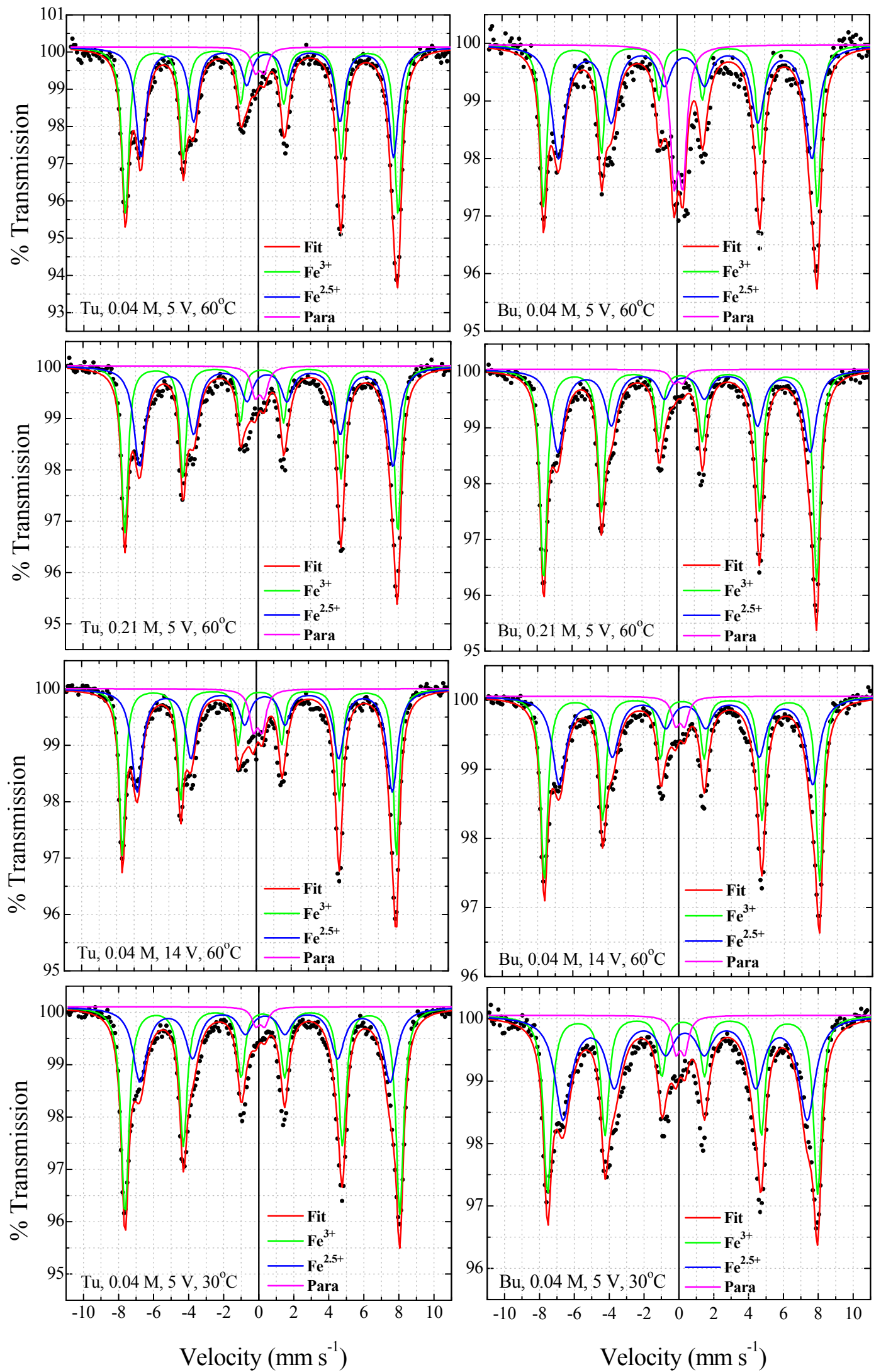
Figure 8. The dependence of the paramagnetic doublet contribution, the ratio of $\mathrm{Fe}^{2.5+}$ to $\mathrm{Fe}^{3+}$ and the nonstoichiometry parameter $\delta$ as a function of growth parameters for all samples (left column, $V$ and $T$ at $5 \mathrm{~V}$ and $60^{\circ} \mathrm{C}$, middle column, $C$ and $T$ at $0.04 \mathrm{M}$ and $60{ }^{\circ} \mathrm{C}$; right column, $C$ and $V$ at $0.04 \mathrm{M}$ and $5 \mathrm{~V}$ ). The circled point refers to the sample with an secondary iron phase.
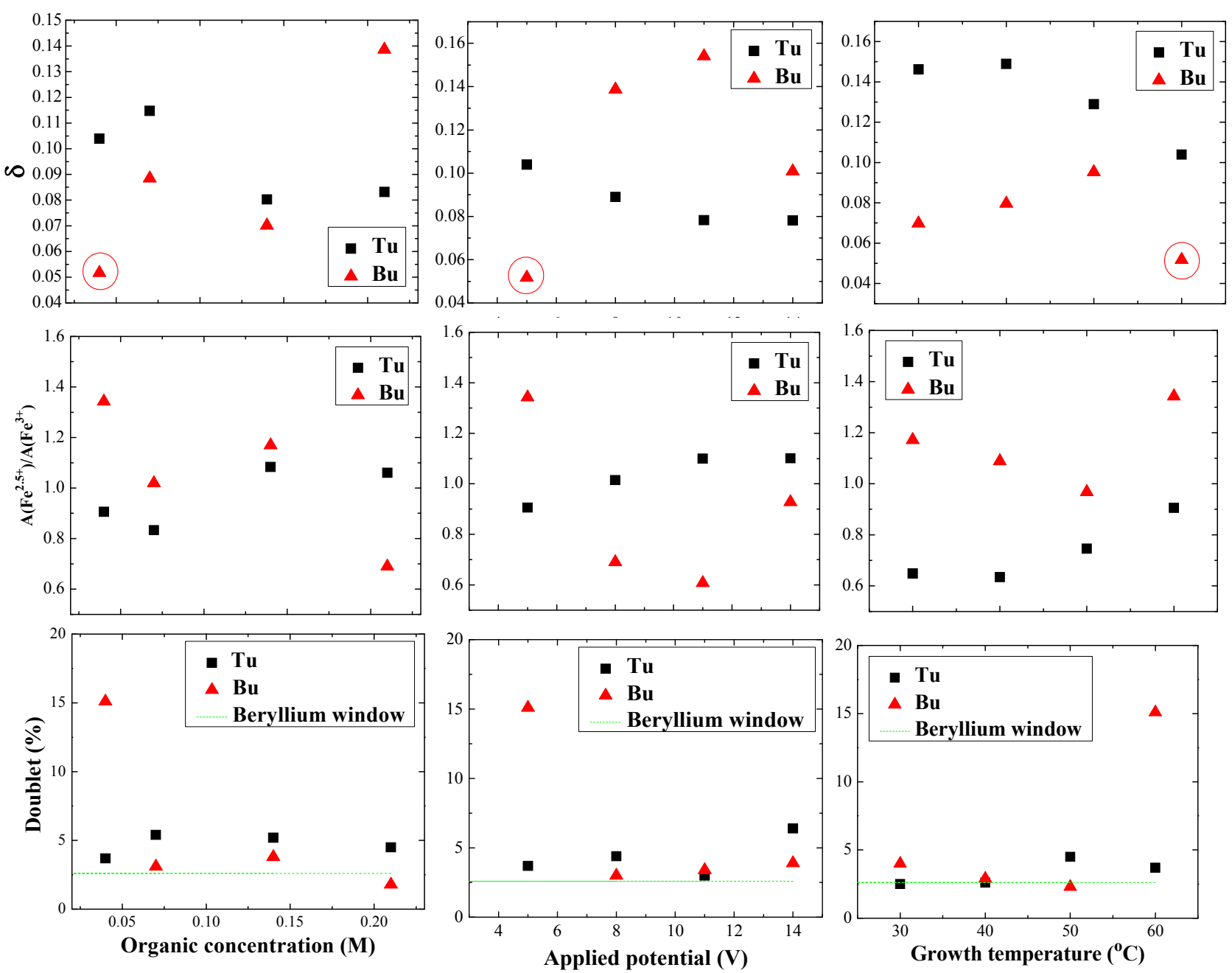

\section{Experimental Section}

\subsection{Materials}

Thiourea $(\mathrm{Tu})$ and sodium butanoate $(\mathrm{Bu})$, were purchased from Sigma-Aldrich Chemical Co. Sodium sulfate anhydrous supplied by BDH limited Poole England and iron sheet (purity 99.5\%) was purchased from Advent Research Materials.

\subsection{Methods}

Magnetite nanoparticles were synthesized by electro-crystallization of iron using a chronoamperometric technique in the presence of an organic stabilizer from an aqueous medium [26,27]. Two purified iron plates of $1 \times 4 \mathrm{~cm}^{2}$ and $1 \times 1 \mathrm{~cm}^{2}$ were used as cathode and anode, respectively. The electrodes were polished with fine-grain emery paper and ultrasonically cleaned with ethanol. Two cleaned electrodes 
were placed a distance of $1 \mathrm{~cm}$ apart from each other in an electrochemical cell containing a solution of one of two different organic additives: $\mathrm{Tu}$ and $\mathrm{Bu}$, with $0.25 \mathrm{M}$ sodium sulfate anhydrous salt as the electrolyte. At the beginning of the experiment when the potential was imposed, the solution was colorless. After applying an appropriate potential difference using a Solartron Instruments SI 1280B electrochemical measurement unit, water is reduced to hydrogen and hydroxyl anions at the cathode and the iron anode is oxidized to $\mathrm{Fe}^{2+}$ and $\mathrm{Fe}^{3+}$. Therefore in the solution, $\mathrm{Fe}^{2+}, \mathrm{Fe}^{3+}$ and $\mathrm{OH}^{-}$meet to react and produce an orange-brown iron hydroxide, which then dehydrates to form a black magnetite, $\left(\mathrm{Fe}_{3} \mathrm{O}_{4}\right)$ precipitate. The reaction time was chosen as $30 \mathrm{~min}$ and the electrolyte temperature was controlled using a thermostatic water bath. The black precipitates were separated from the reaction medium using a Nd-Fe-B permanent magnet and washed several times with a copious amount of DI water and let dry.

In order to investigate the effect of organic additive concentration, applied potential, and growth temperature on structure and particle magnetic properties, six different series of samples named $C_{\mathrm{Tu}}$, $C_{\mathrm{Bu}},(0.04,0.07,0.14,0.21 \mathrm{M})$, and $V_{\mathrm{Tu}}, V_{\mathrm{Bu}}(5,8,11,14 \mathrm{~V})$, as well as $T_{\mathrm{Tu}}, T_{\mathrm{Bu}},\left(30,40,50,60{ }^{\circ} \mathrm{C}\right)$ were synthesized in the presence of either $\mathrm{Tu}$ or $\mathrm{Bu}$ as organic additive. For each organic, samples were first synthesized at four different concentrations. The $0.04 \mathrm{M}$ concentration was used at different voltages, and finally $0.04 \mathrm{M}$ and $5 \mathrm{~V}$ materials were synthesized at different temperatures.

The crystal structure of the products was determined by a Philips X-ray diffractometer, using $\mathrm{CuK}_{\alpha}$ radiation $(\lambda=1.5405 \AA)$ generated at $40 \mathrm{kV}$ and $40 \mathrm{~mA}$. An FEI Titan high resolution transmission electron microscope (HRTEM) and a Carl Zeiss Ultra Plus scanning electron microscope (SEM) were employed to investigate the particle size, morphology, and nanostructure of the magnetite particles. Magnetic measurements were carried out using a home-made vibrating-sample magnetometer (VSM) with a $1.1 \mathrm{~T}$ permanent magnet flux source. Mössbauer spectra in the transmission geometry were recorded for all samples using a $\mathrm{Co}^{57}$ source in $\mathrm{Rh}$. Isomer shifts are quoted relative to the source.

\section{Conclusions}

The results of our study on the effect of the experimental conditions on structural and magnetic properties of electrocrystallized magnetite nanoparticles in the presence of different organic molecules show that temperature, voltage and concentration all play a significant role in determining the morphological, structural, and magnetic properties of the nanoparticles produced. The particle size and morphology were found to be easily modified by the concentration of organic agent, applied potential, or the temperature of the bath. Magnetometry showed that the specific magnetization value of the $\mathrm{Fe}_{3} \mathrm{O}_{4}$ nanoparticles ranges from 45 to $90 \mathrm{Am}^{2} \mathrm{~kg}^{-1}$, depending on the type of organic molecules and experimental conditions, but much of this variation is actually due to the mass of attached, nonmagnetic organic material rather than any change in stoichiometry of the $\mathrm{Fe}_{3-\delta} \mathrm{O}_{4}$. Analysis of Mössbauer spectra showed that by tuning the growth parameters, it is possible to effectively remove a paramagnetic phase, associated with organometallic complexes containing $\mathrm{Fe}^{3+}$ which were present in samples prepared with $\mathrm{Bu}$. The iron is then exclusively present in the form of slightly nonstoichiometric magnetite, with nonstoichiometry parameter $\delta \approx 0.1$. 


\section{Acknowledgments}

This work was enabled by the CRANN Advanced Microscopy Laboratory [AML], Trinity College Dublin. The work was supported by Science Foundation Ireland as part of the NISE project, contract number NISE 10/IN1.I3006. We are grateful to Karl Ackland for the TEM imaging. S.M. and I.K. also thank Shahid Chamran University for financial support.

\section{Conflict of Interest}

The authors declare no conflict of interest.

\section{References}

1. Mørup, S.; Hansen, M.F.; Frandsen, C. Comprehensive Nanoscience and Technology; Oxford Academic Press: Kongens Lyngby, Denmark, 2011; Volume 1, Chapter 14, pp. 437-491.

2. Pankhurst, Q.A.; Thanh, N.T.K.; Jones, S.K.; Dobson, J. Progress in applications of magnetic nanoparticles in biomedicine. J. Phys. D 2009, 42, 1-15.

3. Prina-Mello, A.; Whelan, A.M.; Atzberger, A.; McCarthy, J.E.; Byrne, F.; Davies, G.L.; Coey, J.M.D.; Volkov, Y.; Guńko, Y.K. Comparative flow cytometric analysis of amino functionalized nanowire and nanoparticle signatures. Small 2010, 6, 247-255.

4. Probst, C.E.; Zrazhevskiy, P.; Gao, X. Rapid multitarget immunomagnetic separation through programmable DNA linker displacement. J. Am. Chem. Soc. 2011, 133, 17126-17129.

5. Dobson, J. Remote control of cellular behaviour with magnetic nanoparticles. Nat. Nanotechnol. 2008, 3, 139-143.

6. Medintz, I.L.; Uyeda, H.T.; Goldman, E.R.; Mattoussi, H. Quantum dot bioconjugates for imaging, labelling and sensing. Nat. Mater. 2005, 4, 435-446.

7. Luque, G.L.; Ferreyra, N.F.; Leyva, G.; Rivas, G.A. Characterization of carbon paste electrodes modified with manganese based perovskites-type oxides from the amperometric determination of hydrogen peroxide. Sens. Actuators B 2009, 142, 331-336.

8. Comba, F.N.; Gutierrez, F.; Herrasti, P.; Rubianes, M.D.; Rivas, G.A. Effect of the incorporation of proteins on the performance of carbon paste electrodes modified with electrogenerated magnetite nanoparticles towards the reduction of hydrogen peroxide. Electroanalysis 2012, 24, 1541-1546.

9. Li, J.; Quia, X.; Lin, Y.; Liu, X.; Gao, R.; Wang, A. A study of modified $\mathrm{Fe}_{3} \mathrm{O}_{4}$ nanoparticles for the synthesis of ionic ferrofluid. Appl. Surf. Sci. 2010, 256, 6977-6981.

10. Kumar, C.S.S.R.; Mohammad, F. Magnetic nanomaterials for hyperthermia-based therapy and controlled drug delivery. Adv. Drug Delivery Rev. 2011, 63, 789-808.

11. Qu, J.; Liu, G.; Wang, Y.; Hong, R. Preparation of $\mathrm{Fe}_{3} \mathrm{O}_{4}$-chitosan nanoparticles used for hyperthermia. Adv. Powder Technol. 2010, 21, 461-467.

12. Basti, H.; Ben Tahar, L.; Smiri, L.S.; Herbst, F.; Vaulay, M.-J.; Chau, F.; Ammar, S.; Benderbous, S. Catechol derivatives-coated $\mathrm{Fe}_{3} \mathrm{O}_{4}$ and $\gamma-\mathrm{Fe}_{2} \mathrm{O}_{3}$ nanoparticles as potential MRI contrast agents. J. Colloid Interface Sci. 2010, 341, 248-254. 
13. Mohapatra, S.; Mallick, S.K.; Maiti, T.K.; Ghosh, S.K.; Pramanik, P. Synthesis of highly stable folic acid conjugated magnetite nanoparticles for targeting cancer cells. Nanotechnology 2007, 18, 385102.

14. Xu, P.; Zeng, G.M.; Huang, D.L.; Feng, C.L.; Hu, S.; Zhao, M.H.; Lai, C.; Wei, Z.; Huang, C.; Xie, G.X.; et al. Use of iron oxide nanomaterials in wastewater treatment: A review. Sci. Total Environ. 2012, 424, 1-10.

15. Wu, Y.; Zhang, J.; Tong, Y.; Xu, X. Chromium (VI) reduction in aqueous solutions by $\mathrm{Fe}_{3} \mathrm{O}_{4}$-stabilized $\mathrm{Fe}^{\circ}$ nanoparticles. J. Hazard. Mater. 2009, 172, 1640-1645.

16. Bedanta, S.; Kleemann, W. Supermagnetism. J. Phys. D 2009, 42, 1-28.

17. Gubin, S.P.; Koksharov, Y.A.; Khomutov, G.B.; Yurkov, G.Y. Magnetic nanoparticles: Preparation, structure and properties. Russ. Chem. Rev. 2005, 74, 489-520.

18. Indira, T.K.; Lakshmi, P.K. Magnetic nanoparticles-A review. Int. J. Pharm. Sci. Nanotechnol. 2010, 3, 1035-1042.

19. Frey, N.A.; Peng, S.; Cheng, K.; Sun, S. Magnetic nanoparticles: synthesis, functionalization, and applications in bioimaging and magnetic energy storage. Chem. Soc. Rev. 2009, 38, 2532-2542.

20. Amara, D.; Felner, I.; Nowik, I.; Margel, S. Synthesis and characterization of Fe and $\mathrm{Fe}_{3} \mathrm{O}_{4}$ nanoparticles by thermal decomposition of tri-iron dodecacarbonyl. Colloids Surf. A 2009, 339, 106-110.

21. Liu, J.; Sun, B.; Hu, J.; Pei, Y.; Li, H.; Qiao, M. Aqueous-phase reforming of ethylene glycol to hydrogen on $\mathrm{Pd} / \mathrm{Fe}_{3} \mathrm{O}_{4}$ catalyst prepared by co-precipitation: Metal-support interaction and excellent intrinsic activity. J. Catal. 2010, 274, 287-295.

22. Liu, Y.; Liu, P.; Su, Z.; Li, F.; Wen, F. Attapulgite- $\mathrm{Fe}_{3} \mathrm{O}_{4}$ magnetic nanoparticles via co-precipitation technique. Appl. Surf. Sci. 2008, 255, 2020-2025.

23. Chen, D.; Ni, S.; Chen, Z. Synthesis of $\mathrm{Fe}_{3} \mathrm{O}_{4}$ nanoparticles by wet milling iron powder in a planetary ball mill. China Particuol. 2007, 5, 357-358.

24. Gao, G.; Huang, P.; Zhang, Y.; Wang, K.; Qin, W.; Cui, D. Gram scale synthesis of superparamagnetic $\mathrm{Fe}_{3} \mathrm{O}_{4}$ nanoparticles and fluid via a facile solvothermal route. CrystEngComm 2011, 13, 1782-1785.

25. Wei, W.; He, Q.; Jiang, C. Magnetic iron oxide nanoparticles: Synthesis and surface functionalization strategies. Nanoscale Res. Lett. 2008, 3, 397-415.

26. Cabrera, L.; Gutierrez, S.; Menendez, N.; Morales, M.P.; Herrasti, P. Magnetite nanoparticles: Electrochemical synthesis and characterization. Electrochim. Acta 2008, 53, 3436-3441.

27. Kazeminezhad, I.; Mosivand, S.; Farbod, M. Effect of growth parameters on structure of electrooxidized $\mathrm{Fe}_{3} \mathrm{O}_{4}$ magnetic nanoparticles. Curr. Nanosci. 2011, 7, 819-824.

28. Cabrera, L.I.; Martínez, M.; Reyman, D.; Crespo, P.; Morales, M.P.; Herrasti, P. One single-step synthesis of multifunctional methyleneblue-coated magnetite nanoparticles. J. Nanopart. Res. 2011, 13, 6931-6939.

29. Kazeminezhad, I.; Mosivand, S. Effect of surfactant concentration on size and morphology of sonoelectrooxidized $\mathrm{Fe}_{3} \mathrm{O}_{4}$ nanoparticles. Curr. Nanosci. 2012, 8, 623-627.

30. Mosivand, S.; Monzon, L.M.A.; Ackland, K.; Kazeminezhad, I.; Coey, J.M.D. The effect of organics on the structure and magnetization of electro-synthesised magnetite nanoparticles. J. Nanopart. Res. 2013, submitted for publication. 
31. Abdulwahab, K.; Malik, M.A.; O’Brien, P.; Govender, K.; Muryn, C.A.; Timco, G.A.; Tuna, F.; Winpenny, R.E.P. Synthesis of monodispersed magnetite nanoparticles from iron pivalate clusters. Dalton Trans. 2013, 42, 196-206.

32. Coey, J.M.D.; Mlack, J.T.; Venkatesan, M.; Stamenov, P. Magnetization process in dilute magnetic oxides. IEEE Trans. Magn. 2010, 46, 2501-2503.

33. Grace, P.J.; Venkatesan, M.; Alaria, J.; Coey, J.M.D.; Kopnov, G.; Naaman, R. The origin of the magnetism of etched silicon. Adv. Mater. 2009, 21, 71-74.

34. Coey, J.M.D. Magnetism and Magnetic Materials; Cambridge University Press: Cambridge, UK, 2010; pp. 243-244.

35. Coey, J.M.D.; Morrish, A.H.; Sawatzky, G.A. A Mössbauer study of conduction in magnetite. J. Phys. Colloques 1971, 32, C1:271-C1:273.

(C) 2013 by the authors; licensee MDPI, Basel, Switzerland. This article is an open access article distributed under the terms and conditions of the Creative Commons Attribution license (http://creativecommons.org/licenses/by/3.0/). 